\title{
Healthcare provision and the psychological, somatic and social impact on people involved in the terror attacks in January 2015 in Paris: cohort study
}

Stephanie Vandentorren, Philippe Pirard, Alice Sanna, Lyderic Aubert, Yvon Motreff, Nicolas Dantchev, Sophie Lesieur, Pierre Chauvin and Thierry Baubet

\section{Background}

Terrorist attacks occurred in Paris in January 2015.

\section{Aims}

To assess the mental health impact and the access to psychomedical care of people exposed to the attacks.

\section{Method}

We implemented an open-cohort design 6 and 18 months after the attacks. Exposed civilians and rescue workers were included according to the exposure criteria A for post-traumatic stress disorder (PTSD) in DSM-5. A face-to-face questionnaire conducted by trained psychologists was used to collect sociodemographic characteristics, exposure level, scores on psychometric scales, an international neuropsychiatric interview and access to care.

\section{Results}

Six months after the attacks, $18 \%$ of civilians reported symptoms of PTSD, 31\% had anxiety disorders and 11\% depression. Among rescue workers, $3 \%$ reported symptoms of PTSD and $14 \%$ anxiety disorders. During the $48 \mathrm{~h}$ following the attacks, $53.2 \%$ of civilian had access to psychomedical care $v$. $35 \%$ of rescue and police staff.

\section{Conclusions}

We found severe psychological consequences, even in people who were less exposed.

\section{Declaration of interest}

None.

\section{Copyright and usage}

(c) The Royal College of Psychiatrists 2018

\section{Post traumatic disorders after terrorist attacks}

Acts of terrorism are becoming increasingly common throughout the world. Among survivors and witnesses mental and physical health, social relationships and quality of life may be affected for months or years. ${ }^{1-4}$ A substantial body of research carried out after terrorist attacks in New York, Madrid and Utøya has documented how terrorism can affect mental health. ${ }^{5,6}$ The prevalence of post-traumatic stress disorder (PTSD) 3 months after these attacks were $20 \%$ among those living near the world trade centre in New York, $12 \%$ in the population of Alcalà in Spain ${ }^{3}$ and $11 \%$ among individuals on Utøya Island. ${ }^{6}$ A recent review of the literature of first responders after mass killings found a prevalence of PTSD ranging from 1.3 to $22 \%$ depending on the type of first responder. $^{8}$

PTSD is a condition where symptoms evolve in the aftermath of an extreme traumatic stressor that overwhelms the individual's coping capacities. Although complete recovery occurs within 3 months in about $50 \%$ of patients, many PTSD symptoms may last longer than 12 months after the trauma. ${ }^{9}$ In terms of terrorist attacks, survival analysis shows that more than a third of people who develop PTSD fail to recover even after many years. ${ }^{10,11}$ PTSD is frequently associated with comorbidities such as depression, ${ }^{12,13}$ anxiety disorders with somatic manifestations ${ }^{11}$ and substance use. ${ }^{14}$ Rates of these comorbidities are higher in populations exposed to terrorist attacks. ${ }^{11,15}$ These comorbidities can be explained by physiopathological pathways. Somatic manifestations in patients with PTSD are most likely the consequences of the culmination of several processes: PTSD is associated with significant alterations in both the hypothalamic-pituitary-adrenal (HPA) axis and the sympatho-adrenal medullary (SAM) axis. Neuroimaging has shown greater activation of the amygdala and insula in patients with social anxiety disorder, phobia or PTSD than in controls. These two parts of the brain are involved in fear conditioning and perception of bodily states. ${ }^{11}$ Furthermore the consequences of PTSD on familial, professional and social relationships seriously impact well-being, and are markers of both mental health disorders and source of prolonged stress and depression. ${ }^{15}$ Some studies suggest that the risk of depression following a disaster may be caused by personal loss as a result of the event rather than the experience of severe acute psychological trauma. However, additional data are needed to corroborate or refute this hypothesis. ${ }^{16}$

\section{Terrorist attacks in France}

In France, the prevalence of PTSD in the country's population after waves of terrorist attacks in 1982 and 1995 ranged from 8 to 30\%, 5,17 decreasing over time. ${ }^{18}$ Since July 1995 , medicopsychological emergency teams (CUMP) have ensured urgent medicopsychological care for victims of psychotraumatic events. The first wave of 2015 terror attacks in Paris occurred on the 7, 8 and 9 January 2015 including: (a) the massacre of the staff of the Charlie Hebdo magazine and the killing of a police officer, (b) the killing of a second police officer in a Parisian suburb, (c) the killing in a kosher grocery store of hostages and (d) the killing of two terrorists in a building where they were hiding. In total, 17 people were killed and 20 injured.

Santé publique France, the French national agency for public health, launched a cohort study (entitled IMPACTS) to assess the mental health and psychosomatic impact of the attacks on the public and first responders. Its purpose is to measure changes over time in the familial and occupational dimensions of the lives of those affected, its interactions with mental health and to assess the associated care and support these people are provided.

The aim of this paper is to describe the health, social and somatic impacts of the January 2015 terror attacks in Paris - as a 
function of the individual degree of exposure - on civilians and trained professionals, 6 months after the attacks occurred. The paper also provides a first insight into healthcare utilization in those months.

\section{Method}

\section{Population recruitment}

People at least 16 years old, who had been exposed to one or more of the above-mentioned terrorist attacks and who met the "Stress" criterion of the Post Traumatic Stress Condition Definition in the 5th edition of the Diagnostic and Statistical Manual of Mental Disorders, ${ }^{19}$ were eligible for inclusion in IMPACTS. This stress criterion stipulates that a person must be exposed to death, threatened with death, or exposed to or threatened with serious injury, as follows (one required): direct exposure, witnessing the event from a distance, learning that a relative or close friend was exposed to trauma, repeated or extreme indirect exposure to aversive details of the trauma, usually in the course of professional duties.

More specifically, to be included, first responders had to be police officers, or emergency or rescue workers (volunteers or professionals), exposed during the first $12 \mathrm{~h}$ after the event. Individuals from the civilian population were considered to be directly threatened when they had suffered from physical injuries or had been taken hostage or had been directly threatened by death or physical injury. They were considered to be indirectly threatened when they were physically present at the scene of the events and had seen someone being threatened, injured or dying or had seen blood, bodies or heard someone dying. We included and defined as 'witnesses' individuals who were at home or working in close proximity to the events when they occurred and who directly witnessed the attacks (not through media exposure) without being directly involved. Family members and close relatives of victims (persons murdered, injured or taken hostage) were also included.

Two enrolment methods were used. For the civilian population, recruitment was proposed by people listed by the authorities and by caregivers as victims, witnesses or relatives of the victims. Additionally, we targeted people living or working near the sites of the events. Invitation letters were dropped into the mail-boxes of households and companies located within a $100 \mathrm{~m}$ radius of the places where the attacks occurred. Persons invited to participate in the inclusion phase could do so either through a web-based inclusion questionnaire or by sending back a completed paperbased inclusion questionnaire in a pre-addressed postage-paid envelope. For first responders, recruitment was implemented via information provided by the institutions involved in the response to the attacks. Written informed consent was obtained for all the participants.

\section{Data collection, description and statistical analysis}

Clinical psychologists administered face-to-face structured interviews with the participants. These professionals were trained in trauma management and performed a psychological analysis. When needed, they directly referred participants to care.

The questionnaires collected data on sociodemographic characteristics (gender, age, marital status, occupational and socioeconomic status, level of education), social support (perceived quality of support from their social network), history of psychological disorders and previous exposure to a traumatic event during their lifetime. For first responders, their level of training in coping with psychotraumatic events was also explored.
Information on the care and institutional (medical, psychological, association based) support received within $48 \mathrm{~h}$, between 2 and 7 days and after a week following the attacks was recorded. The reasons for not seeking (or refusing) care were also recorded. The degree of exposure to the attacks was explored. Reported peritraumatic reaction was analysed using the Shortness of Breath, Tremulousness, Racing heart and Sweating scale (STRS, a retrospective description of the somatic manifestations of fear) ${ }^{20}$ and the Peritraumatic Dissociative Experience Questionnaire (PDEQ, which measures peritraumatic dissociative symptoms). ${ }^{21}$

The following consequences of the events were explored: sick leave from work after the attacks; the economic impact on the company in which the person worked; the onset or worsening of somatic disorders needing healthcare; and consumption of psychoactive substances (alcohol, cigarette/cannabis). The participant's perception of the intensity of the impact of the events on his/her professional, social life and family lives was evaluated using the the Sheehan scale, ${ }^{22,23}$ where the perceived impact scores range from 0 (no impact) to 10 (very strong impact) for professional, social and domestic lives. The overall score (from 0 to 30 ) is the sum of the three different scales.

We used validated scales to have a dimensional measure of the intensity of symptoms present in a post-traumatic stress state, for example the Post-Traumatic Stress Disorder CheckList (PCL-S). ${ }^{24}$ This dimensional approach enabled us to measure the intensity of symptomatic manifestations (subsyndromic disorders), and to identify the individuals who could benefit from care. We also used modules in version 6 of the Mini-International Neuropsychiatric Interview (MINI) questionnaire to diagnose depression, suicide risk, panic disorder, agoraphobia, social phobia, PTSD, psychoactive substance disorders and generalised anxiety. ${ }^{25}$ Using this 'categorical' questionnaire made it possible to explore the frequency of mental health disorders. In addition, to provide a global clinical assessment of the level of psychological distress, interviewers were asked to code on a numerical scale the overall severity of the general condition mental health of the respondents (Clinical Global Impression (CGI) questionnaire). ${ }^{26}$

We performed univariate analysis of the relationship between the impact on mental health and the degree of exposure, using a $\chi^{2}$-test or Fisher's test for qualitative variables as relevant, and the Kruskal-Wallis test for quantitative variables. Analyses were carried out using R (R 3.2.1) statistical software. All tests were performed with a bilateral significance level of $5 \%$.

\section{Results}

\section{Participation rates and follow-up}

In total, 978 people responded to our invitation to participate (Fig. 1): 226 did not meet the inclusion criteria (23\%). Of the remaining 752, 186 refused to participate, 49 agreed to be contacted but only during the second stage, 85 did not respond and 432 agreed to an individual interview (10 of the latter were finally excluded). Therefore, among the 752 people constituting the total cohort population, the overall participation rate was $56 \%$. The reported reasons for refusal to participate were different between first responders (lack of time: 44\%) and civilians (desire not to re-live the painful event: $33 \%)$. Participants were younger than non-participants: 39 v. 52 years $(P<0.001)$.

At the first interview, the study population $(n=422)$ included 190 civilians and 232 first responders (19\% professional medical rescue workers, $26 \%$ firefighters, $24 \%$ police officers and $31 \%$ volunteers). The first cohort consultation took place 6 to 9 months after the January 2015 events. 


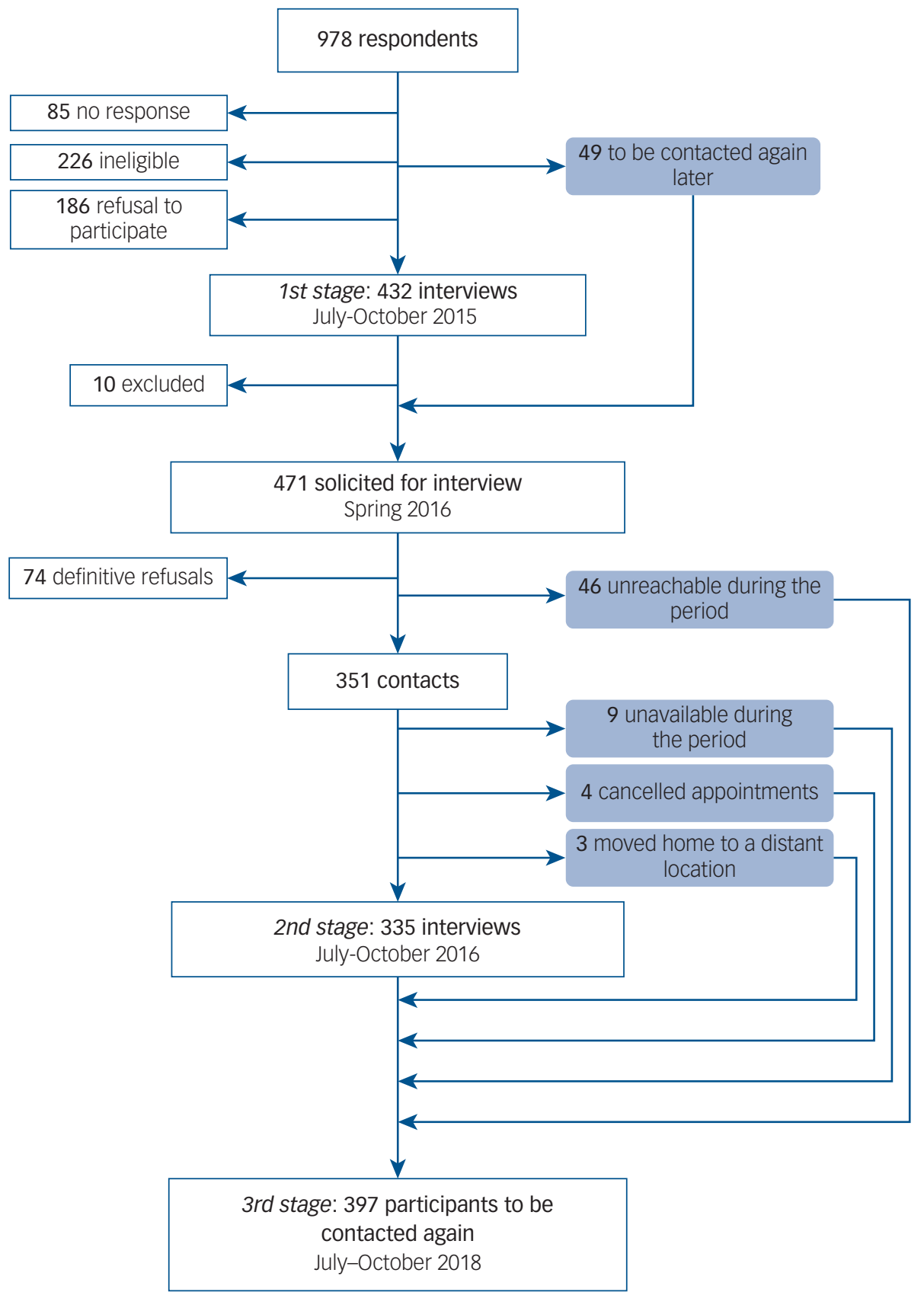

Fig. 1 Flow diagram.

Those who answered these questionnaires were due to be interviewed face to face between a year and 18 months later (June to October 2016). Forty-nine people who were too vulnerable and/or still in too much shock to participate in the first stage of consultation were included in this stage. However, 74 people ( $16 \%$ of the total cohort population) refused to participate in this second stage investigation period and 46 others were unreachable during this secondstage investigation period. Therefore, a total of 351 interviews were scheduled. Only 335 interviews were actually performed, however, as nine police members were unavailable (due to policing duties arising from UEFA Euro 2016 and the Nice terrorist attacks), three participants had moved away from Paris and four appointments were cancelled. The third stage of cohort consultation, for which 397 participants are set to be contacted, is planned to take place between July and October 2018.

\section{Population characteristics}

Cohort key characteristics at first visit are shown in Table 1. For the civilian population and first responders, the $\mathrm{M} / \mathrm{F}$ sex ratio was, respectively, 0.65 and 2.2 (5.7 for firefighters and 1.0 for medicopsychological staff). The civilian population was older with a median age of 41 years $v$. 36 years among first responders (30 years for volunteers and 47 years among medicopsychological staff). The majority of both the civilian population (57\%) and first responders $(62 \%)$ were living in a couple. 
Table 1 Sociodemographic characteristics and exposure of first responders and civilians in the IMPACTS study

Civilians

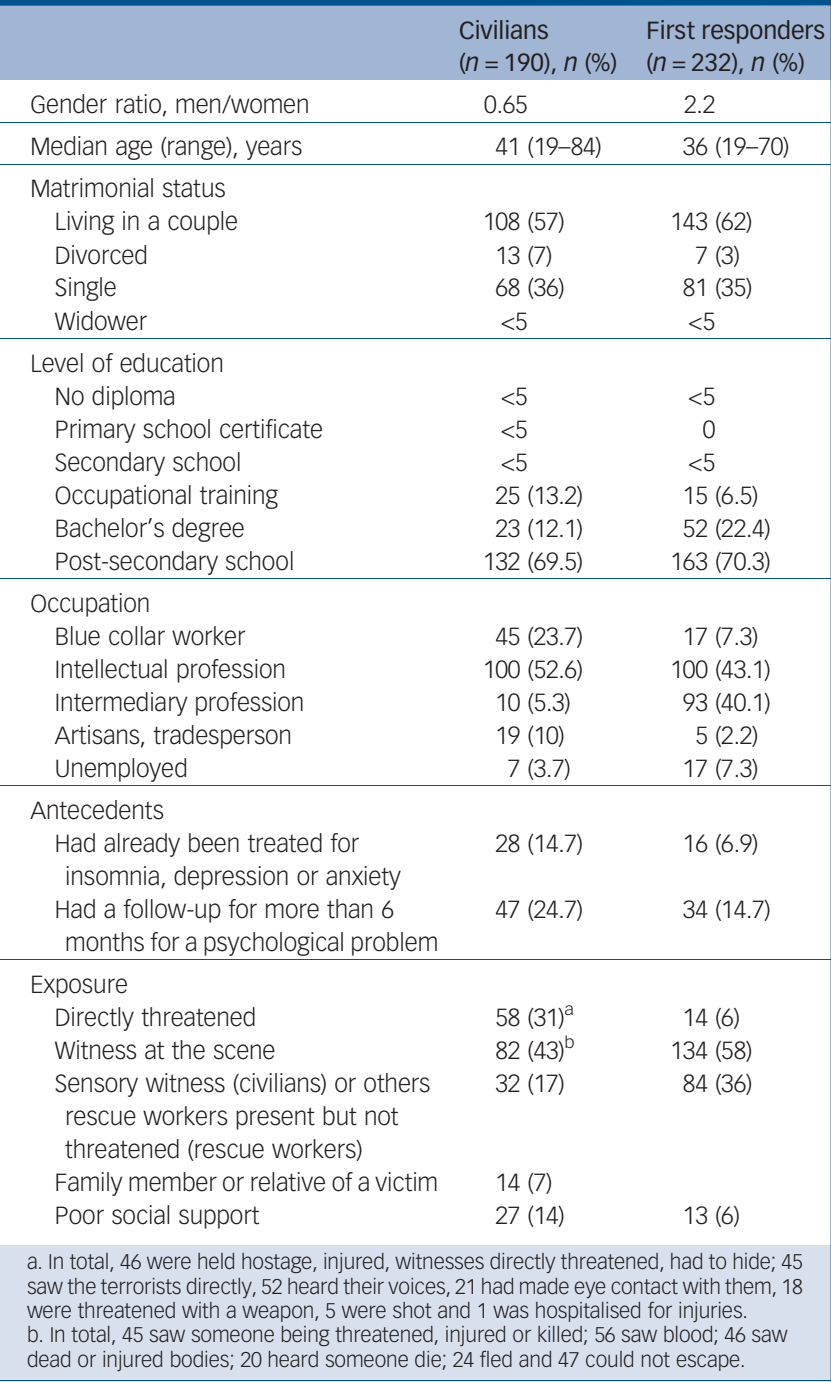

With respect to civilians' socioprofessional status, $82 \%$ were in employment. Among police officers, firefighters and health rescue workers, respectively, 91, 100 and 97\% were professionals while 9 , 0 and $2 \%$ were retired. For volunteer-association rescue workers $72 \%$ were employed, $21 \%$ were students and $7 \%$ were unemployed.

With regard to the social environment, more than $85 \%$ of the civilian population and $94 \%$ of the rescue workers declared that they had good support. For first responders, a strong sense of unity was important and $86.3 \%$ declared that they knew a key person in their institution who could help them.

Before the attacks, $25 \%$ of the civilian participants had a followup for more than 6 months for a psychological problem, and $14.7 \%$ had already been treated for insomnia, depression or anxiety. For first responders, these values were, respectively, 15 and $7 \%$.

\section{Population exposures}

Among the civilian population, 58 people had been directly threatened; 82 were indirectly threatened; 32 were witnesses; 14 were exclusively family members or relatives of a person killed, injured or taken hostage. The peritraumatic response (PDEQ - reaction of dissociation) median score was 14 (range of the PDEQ 0-40) and the STRS (adrenergic reaction) median score was 23 (range of the STRS 0-52). The coefficient alpha of Cronbach, estimating the internal consistency of these scores, was respectively 0.88 and
0.86. These scores display a gradient as a function of exposure (Fig. 2).

Among first responders, 14 had been directly threatened and 134 indirectly threatened. A large proportion of rescue workers had cumulative exposure as they had been involved in rescue operations in several of the attacks which happened in January 2015 (35\%). The peritraumatic response (PDEQ - reaction of dissociation) median score was 3 (range of the PDEQ 0-33) and the STRS (adrenergic reaction) median score was 10 (range of the STRS 0-48). Cronbach's Alpha coefficient, estimating the internal consistency of these scores, was respectively 0.88 and 0.81 .

\section{The psychotraumatic impact}

Table 2 summarises the impact of the terror attacks among civilians and rescue workers, according to the groups of exposure (rescue workers $v$. civilians).

Among rescue workers, PTSD was diagnosed in seven (3\%) people: three directly threatened, three indirectly threatened and one who was not threatened. Of these seven, six had no specific training and four received support within the first $48 \mathrm{~h}$. With respect to the PCL-S, 18 (8\%) participants had a score $\geq 33$ (8 of whom had a score $>44)$. Among first responders $32(14 \%)$ had at least one anxiety disorder.

Among civilians, the CGI clinical assessment of psychological distress found that $23.2 \%(n=44)$ were slightly or moderately affected, $13.7 \%(n=26)$ were severely affected and $3.2 \%(n=6)$ very severely affected. The remaining $59.9 \%$ had a normal or borderline psychological state. The median PCL score was 31 , the levels depending on the level of exposure. A total of $25 \%(n=48)$ had a PCL-S score consistent with possible PTSD ( $>44)$, and $17 \%$ ( $n=33)$ had a score $\geq 33$. Finally, 34 people $(18 \%)$ were diagnosed with PTSD. Its frequency depending on the level of exposure: $3 \%$ in witnesses, $12.2 \%$ in those indirectly threatened, $36 \%$ in those who were close relatives of victims and $31 \%$ in those directly threatened $(P=0.03$, Table 2$)$. Women were more likely to have PTSD than men $(32 \%$ v. $12 \%, P=0.057)$. Marital status and socioprofessional status were not statistically different between people with and without PTSD. However, the former declared having sufficient social support less frequently $(16 \% v .84 \%, P<0.001)$.

Current depressive episodes were detected in 20 civilians (11\%), with differences depending on exposure (19\% among those directly threatened, $P=0.05)$. In total, 52 civilians $(27 \%)$ had a non-zero suicide risk (25\%, $n=9$, in witnesses, $27 \%, n=22$, in those indirectly threatened, $14.3 \%, n=2$, in bereaved/close relatives and 32.8\%, $n=19$, in those directly threatened). Among them, a moderate or high suicide risk was found in six people (3\%). Moreover, 59 people (31\%) had at least one listed anxiety disorder. Reporting an anxiety disorder also depended on the exposure level and differences were statistically significant: $38 \%$ among those directly threatened, $28 \%$ in indirectly threatened, $28 \%$ witnesses and $29 \%$ in close relatives. The most common disorders reported were agoraphobia $(26 \%, n=49,43$ of these cases were not associated with panic disorders), social phobia $(5 \%, n=9)$, panic disorder $(n=5)$ and generalised anxiety $(5.3 \%, n$ $=10)$. In the civilian population, $72(38 \%)$ individuals had at least one disorder: $38(20 \%)$ had depression and/or anxiety disorder, 9 (5\%) had PTSD alone, and 25 (13\%) had PTSD and either a depression or anxiety disorder. Depression was very frequently associated with PTSD $(80 \%, n=16 / 20)$. Conversely, people with psychiatric disorders in the absence of PTSD were more frequently affected by one or more anxiety disorders but no reported depressive-related disorder.

\section{The somatic impact}

Among first responders, 47 (20\%) reported seeking healthcare for a non-psychological health problem since the attacks (overwork, 


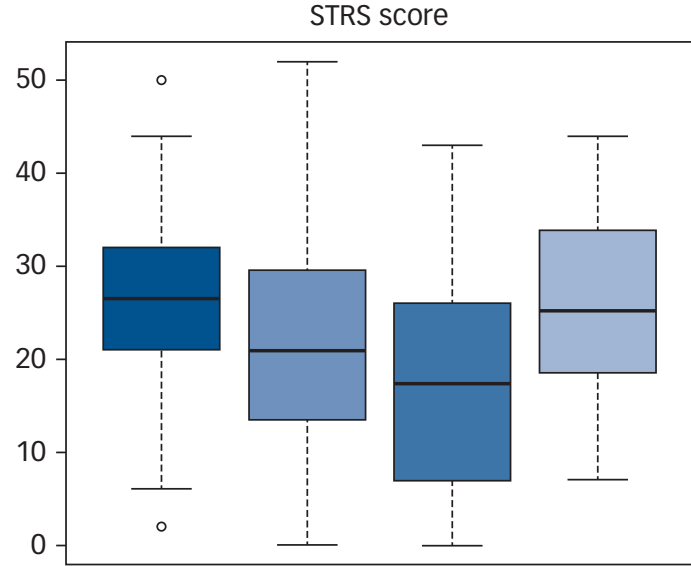

Directly threatened

Indirectly threatened
PDEQ score

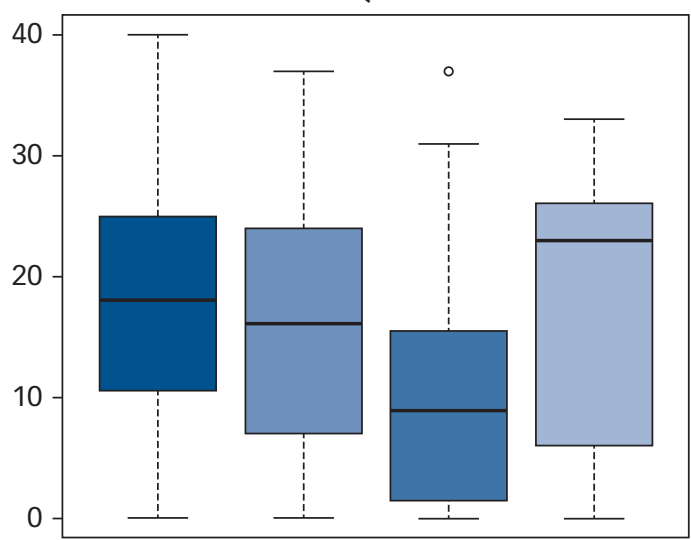

Witnesses

Relatives

Fig. 2 Shortness of Breath, Tremulousness, Racing heart and Sweating (STRS) scale score and Peritraumatic Dissociative Experience Questionnaire (PDEQ) score according to exposure groups in the IMPACTs survey.

fatigue, physical injuries, dermatological, osteoarticular or respiratory problems). Ten of these (21.3\%) said the problem was related to the attacks (subjective attribution). We noted statistically significant differences according to exposure level. Approximately half of these consultations concerned volunteer first responders (49\%).

Among civilians, 83 (44\%) had consulted physicians for a nonpsychological health problem since the attacks, 47 of whom (57\%) saying they thought the problem was related to the attacks. Differences according to the level of exposure were observed. Among those who suffered from both PTSD and a comorbidity, $68 \%(n=17)$ reported consulting a practitioner for a somatic disorder whose origin was attributable to the attacks.

\section{The occupational impact}

Six months after the attacks, 15 (6\%) rescue workers declared they had been unable to work at some point since the attacks. Among them, $11(73 \%)$ were police officers. Differences in the numbers of people declaring inability to work depended on exposure level: ten were directly threatened, four were indirectly threatened and one was involved but not threatened. The median duration of work stoppages was 40 days (range 3-180) days. Among civilians, 48 (25\%) reported being unable to work proficiently due to their health conditions. Six months after the event, $11(6 \%)$ were still not able to return to work.

\section{Impact on of psychoactive substances}

With respect to first responders, $22(9 \%)$ had increased their alcohol, tobacco or cannabis use with 3 (21\%) of the directly threatened, 12 (9\%) of the indirectly threatened and 7 (8\%) of others first responders involved but not threatened in the events.

In the civilian population, $42(22 \%)$ said they had increased their alcohol, tobacco or cannabis use: 17 (29\%) of those directly threatened, 17 (20\%) of the indirectly threatened, 3 of the witnesses and $5(36 \%)$ of close relatives.

\section{Healthcare utilisation}

Half of the first responders $(n=118,51 \%)$ benefited from psychological support provided by their own institution ( $93 \%$ of those directly threatened, $49 \%$ of those indirectly threatened and $46 \%$ of those involved but not threatened).
Among civilians, $53.2 \%$ benefited from immediate medicopsychological care during the first $48 \mathrm{~h}$ after the events, with differences according to exposure level. During the first $48 \mathrm{~h}$ trauma management was mainly provided by the medical-psychological emergency units. Finally, $46.8 \%$ of the people recruited in our survey had no contact with these actors in the immediate post-event period (22.4\% of those directly threatened, $53.7 \%$ of indirectly threatened, $75 \%$ of witnesses and $35.7 \%$ of close relatives). People with immediate contact with psychotrauma professionals after the attacks suffered less frequently from anxiety disorders or depression than people with no immediate contact $(26 \%$ v. $41 \%, P=0.03)$. However the association between immediate care ( $\leq 48 \mathrm{~h})$ by a psychotrauma professional and PTSD was not statistically significant.

\section{Discussion}

\section{Main findings}

Performing studies on the psychological impact over time of a terrorist attack is a challenge because of the unpredictability of the events and the need for prompt action in order to be able to accurately measure the impact. The need for ethical clearance and CNIL (Commission nationale de l'informatique et des libertés) authorization means that such prompt action is more difficult to implement in France than in some other countries. ${ }^{26,27}$ This study, which was implemented promptly within a strong scientific framework available in France, helped to measure the consequences of the January 2015 attacks in Paris on the mental health of the people affected.

In our study, $18 \%$ of civilians reported symptoms of PTSD and 20(10\%) had depression and 59 (32\%) had anxiety disorders. This result is consistent with a previous study on the attack in Utøya island, ${ }^{5}$ where percentages varied according to exposure level: the most affected people being those directly threatened and victims' close relatives. In our study, among the former, we observed a substantial proportion of PTSD (31\%). For victims' close relatives this value was $36 \%$. Furthermore, $12 \%$ of people indirectly threatened in our study had PTSD. For witnesses to the Paris attacks psychological distress was more often associated with anxiety disorders and/or depression $(n=10,28 \%)$. This result has implications for public health: after a major psychotraumatic event, mental health disorders 


\begin{tabular}{|c|c|c|c|c|c|c|c|c|c|c|c|}
\hline 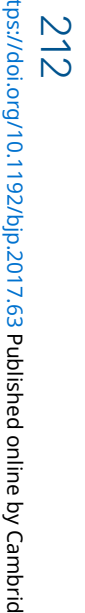 & Table 2 Impact of terror attacks among groups of ex & osure in civilia & and in rescue $y$ & $\begin{array}{l}\text { ers (IMPACTs } \\
\text { Civilians }\end{array}$ & survey) & & & & Rescl & workers & \\
\hline & & $\begin{array}{l}\text { Directly } \\
\text { threatened } \\
(n=58)\end{array}$ & $\begin{array}{l}\text { Indirectly } \\
\text { threatened } \\
(n=82)\end{array}$ & $\begin{array}{l}\text { Witnesses } \\
(n=36)\end{array}$ & $\begin{array}{l}\text { Family member or } \\
\text { close relative } \\
(n=14)\end{array}$ & $\begin{array}{l}\text { Total } \\
(n=190)\end{array}$ & Test $^{\mathrm{a}}$ & $\begin{array}{l}\text { Directly } \\
\text { threatened } \\
(n=14)^{\mathrm{b}}\end{array}$ & $\begin{array}{l}\text { Indirectly } \\
\text { threatened } \\
(n=134)\end{array}$ & $\begin{array}{l}\text { Present but not } \\
\text { threatened } \\
(n=84)\end{array}$ & $\begin{array}{l}\text { Total } \\
(n=232)\end{array}$ \\
\hline & $\begin{array}{l}\text { Psychotrauma impact } \\
\text { PCLs, median (range) }\end{array}$ & $38(17-78)$ & $29(17-78)$ & $24(17-71)$ & $38(21-61)$ & $31(17-78)$ & $<0.001$ & $35(17-65)$ & $23(17-65)$ & $21(17-42)$ & $20(17-65)$ \\
\hline & MINI evaluation & & & & & & & & & & \\
\hline & PTSD, $n(\%)$ & $18(31)$ & $10(12)$ & 1 & $5(36)$ & $34(18)$ & 0.003 & 3 & 3 & 1 & 7 (3) \\
\hline & Depression, $n(\%)$ & $11(19)$ & 4 & 4 & 1 & $20(11)$ & 0.05 & - & 1 & 1 & 2 \\
\hline & Anxiety disorder, $n$ (\%) & $22(38)$ & $23(28)$ & $10(28)$ & 4 & 59 (31) & 0.6 & 1 & $24(18)$ & $7(8)$ & $32(14)$ \\
\hline & suicide risk, $n(\%)$ & $19(33)$ & $22(27)$ & $9(25)$ & $2(14)$ & $52(27)$ & 0.54 & 1 & $20(15)$ & $10(12)$ & $31(13)$ \\
\hline & Clinical evaluation (CGI), $n$ (\%) & & & & & & & & & & \\
\hline & Normal or borderline ill & $28(48)$ & $58(71)$ & $19(53)$ & $6(43)$ & $111(58)$ & 0.038 & $9(64)$ & $107(80)$ & $70(83)$ & $186(80)$ \\
\hline & Mildly or moderately ill & $14(24)$ & $15(18)$ & $10(28)$ & $5(36)$ & $44(23)$ & & $4(29)$ & $20(15)$ & $10(12)$ & $34(15)$ \\
\hline & Markedly or severely affected & $16(28)$ & $11(13)$ & 2 & 3 & $32(17)$ & & 1 & 5 & 3 & $9(4)$ \\
\hline & $\begin{array}{l}\text { Somatic impact: seeking healthcare for non- } \\
\text { psychological health problem }\end{array}$ & $36(62)$ & $28(34)$ & $14(39)$ & 5 & $83(44)$ & 0.005 & 4 & $25(19)$ & $18(21)$ & $47(20)^{c}$ \\
\hline & Occupational impact: work sick leave after the events & $19(33)$ & $21(26)$ & 2 & $6(43)$ & $48(25)$ & 0.013 & $10(71)$ & 4 & 1 & $15(6)$ \\
\hline & $\begin{array}{l}\text { Behavioural impact: declared increased their } \\
\text { consumption of alcohol, tobacco or cannabis since } \\
\text { the events }\end{array}$ & $17(29)$ & $17(21)$ & 3 & $5(36)$ & $42(22)$ & 0.079 & 3 & $12(9)$ & $7(8)$ & $22(9)$ \\
\hline & $\begin{array}{l}\text { a. Statistical analyses were performed by non-parametric tests, Fis } \\
\text { b. Exclusively police. } \\
\text { c. Ten rescue workers among } 47 \text { declare their somatic impact relat } \\
\text { events }(n=2) \text {; respiratory problems }(n=2) \text {; dermatological problen }\end{array}$ & $\begin{array}{l}\text { her and Kruskal-Wa } \\
\text { d to the event (four } \\
s=1) \text { or osteoart }\end{array}$ & $\begin{array}{l}\text { as relevant. Tests } \\
\text { ectly threatened, fo } \\
\text { ar problems }(n=1)\end{array}$ & $\begin{array}{l}\text { only performe } \\
\text { directly threate }\end{array}$ & $\begin{array}{l}\text { on the data for the civil } \\
\text { ed and two others rescu }\end{array}$ & $\begin{array}{l}\text { group because } \\
\text { Norkers): they de }\end{array}$ & $\begin{array}{l}\text { the statistic } \\
\text { eclared prot }\end{array}$ & I power was insu & $\begin{array}{l}\text { ent in the rescue } \\
\text { fatigue or overwo }\end{array}$ & $\begin{array}{l}\text { r group. } \\
=4) \text {, physical injuries it }\end{array}$ & ftermath of \\
\hline
\end{tabular}

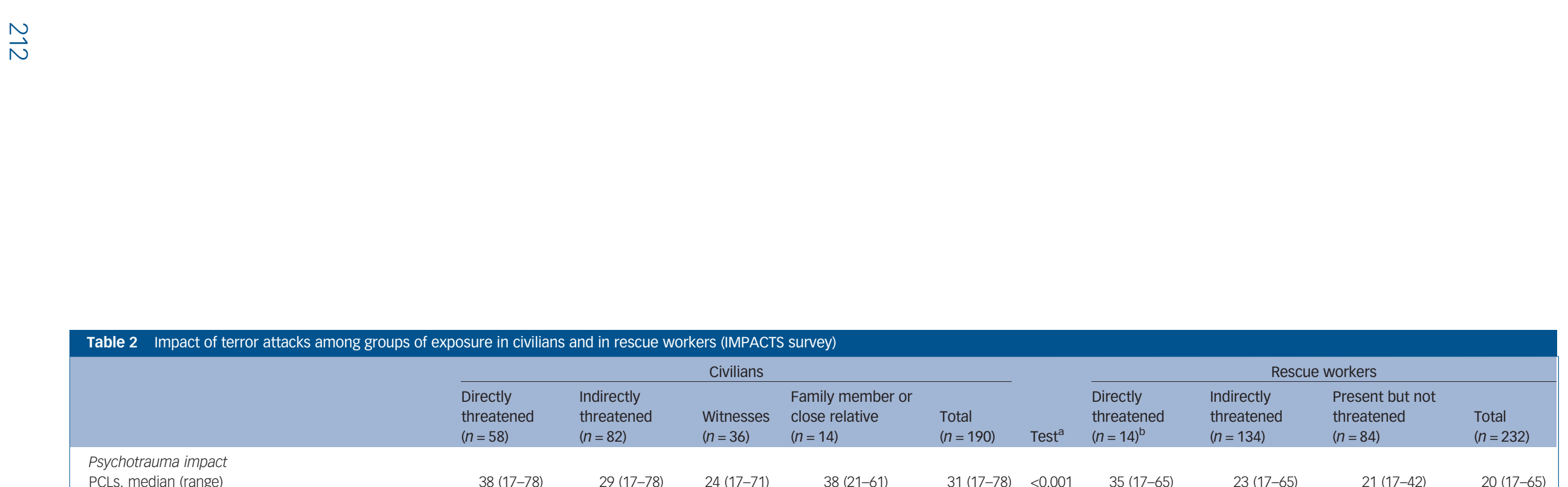

c. Ten rescue workers among 47 declare their somatic impact related to the event (four directly threatened, four indirectly threatened and two others rescue workers): they declared problems related to stress, fatigue or overwork $(n=4)$, physical injuries in the aftermath of
events $(n=2)$; respiratory problems $(n=2)$; dermatological problems $(n=1)$ or osteoarticular problems $(n=1)$ 
can affect people who have not been directly threatened. Among civilians, a quarter had consulted a physician for a non-psychological health problem that they reported was related to the attacks. A third of the civilians studied were unable to work since the attacks.

First responders less frequently reported symptoms of PTSD (3\%) and anxiety disorders (14\%) than civilians. In this trained professional population, the prevalence of PTSD was similar to that found in first responders following the attack in Utøya island in Norway. It is possible that this population underreported its responses because they accumulate a considerable amount of work-related stress. To take into account the combined burden on first responders, we investigated - just as other studies have done - the impact of additional factors including sick-leave, consumption of psychoactive substances and/or alcohol, as well as somatic complaints. Some studies have noted a large proportion of individuals reporting somatic complaints among firefighters following terror attacks. ${ }^{28}$ Looking only for psychiatric disorders is probably not the most effective way to explore the negative health consequences on their mental health after a traumatic event.

More than half of the exposed civilians and half of the professionals had asked for mental health support after the attacks. Although satisfactory for those directly threatened, others felt that the mental health support they had received had room for improvement. Among civilians who reported at least one mental health disorder, $70 \%$ and $30 \%$ of those indirectly and directly threatened, respectively, had received no mental health support. This could be attributed to (a) no proposed follow-up by specialized health professionals, probably due to the insufficient numbers of such professionals in France, or (b) a feeling of lack of legitimate rights to support in witnesses and people indirectly threatened. Indeed, several interviewees stated that they did not feel they had been sufficiently threatened by the attacks to to feel they could complain about their suffering.

\section{Strengths and limitations}

One of the main strengths of this study is the protocol for the recruitment of our population, as it included active field research. International literature to date has focused only on people directly involved in a given event, or in the case of large-scale events, on the general population. However, the recruitment of people living or working in the vicinity of the terrorist attacks (i.e. not directly threatened or witnesses) in our study, showed that this population can also meet the recognised criterion for exposure to a traumatic event (criterion A for PTSD) and can consequently be legally certified as suffering from PTSD. Our approach was effective because $36 \%$ of participating civilians were recruited as a direct result of our active field research (i.e. they had not all been in touch with the emergency and rescue services following the attacks). The choice of using postal return for the inclusion questionnaire allowed us to reach elderly and socioeconomically disadvantaged people (i.e. less common internet-user profiles).

However, the heterogeneity of recruitment could imply that the estimated prevalence of the disorders observed was less accurate. More specifically, those with underlying mental health problems may have been more likely to participate, which could have led to differential selection bias. For the second wave of interviews, 18 months after the attacks, the participant attrition rate was due to two main factors: summer time was not favourable for interviews; and the second terror attack which occurred in November 2016 in the same area as the first attack, led to some people deciding to move away and consequently becoming unreachable. Finally, small numbers meant the study suffered from a lack of statistical power.

\section{Implications}

Despite these limitations, our survey has methodological and ethical strengths. We measured the psychiatric impact using the MINI, which is a structured and validated diagnostic tool and therefore provides the possibility of international comparison. Moreover, the face-to-face interview with psychologists trained in trauma management reinforced the validity of the psychological analysis and was much appreciated by the participants, who were directly referred to care by our interviewer when needed. This represents a strong ethical element in our work. To our knowledge, this is one of the $\mathrm{few}^{31}$ studies to date addressing health care and support utilization after a terrorist attack among first responders.

Our survey also investigated depression, anxiety disorders and the impact felt on daily lives in terms of somatic health, psychoactive substance use and economic consequences. This fact could be of both clinical and public health interest, and could help clinicians to anticipate the needs of different psychotrauma patient groups. Our findings showed that the burden of psychological consequences of terrorist attacks is substantial among large groups in the general population and needs to be addressed by public health initiatives.

More specifically, our results highlight the public health issue of the non-negligible proportion of civilians indirectly threatened by or witnesses to the January 2015 terrorist attacks in Paris, who were suffering from a mental health disorder 6 months after the events, and who had not received any mental health support (70\%). The fact that a quarter of the civilians we studied had consulted a physician for a non-psychological based health problem which they attributed to the attacks deserves special attention in any future research.

Stephanie Vandentorren, PhD, Direction of Regional Office, Santé publique France The French Public Health Agency, Saint Maurice, France and INSERM, Sorbonne Université, Institut Pierre Louis d'Epidémiologie et de Santé Publique IPLESP, Department of social epidemiology, Paris, France; Philippe Pirard, MD, Direction of chronic diseases and injuries, Santé publique France, The French Public Health Agency, Saint Maurice cedex, France; Alice Sanna, MD, Direction of Regional Office, Santé publique France, The French Public Health Agency, Saint Maurice cedex, France; Lyderic Aubert, Direction of Regional Office, Santé publique France, The French Public Health Agency, Saint Maurice cedex, France; Yvon Motreff, Direction of chronic diseases and injuries, Santé publique France, The French Public Health Agency, Saint Maurice cedex, France; Nicolas Dantchev, MD, Hôtel Dieu, Paris, France; Sophie Lesieur, INSERM, Sorbonne Université, Institut Pierre Louis d'Epidémiologie et de Santé Publique IPLESP, Department of social epidemiology, France; Pierre Chauvin, MD, INSERM, Sorbonne Université, Institut Pierre Louis d'Epidémiologie et de Santé Publique IPLESP, Department of social epidemiology, France; Thierry Baubet, PHD, CESP Inserm 1178, Université Paris 13, Paris, France and Hopital Avicenne, Bobigny, France.

Correspondence: Stephanie Vandentorren, Sante publique France, 12 rue du val d'Osne, 94415 Saint Maurice, France. Email: stephanie.vandentorren@santepubliquefrance.fr

First received 17 Jun 2017, final revision 10 Oct 2017, accepted 27 Nov 2017

\section{Funding}

This work was supported by 'Fondation d'Aide aux Victimes du Terrorisme' (FAVT), the Regional Health Agency (ARS) and Santé publique France (the national public health agency).

\section{Acknowledgements}

The authors are most grateful to all the study participants for their involvement especially given the very difficult period for them, to all the interviewers, and to Olivier Gremont, Jérémie Carré, Matthieu Petitclerc, Pierick Bergeran, Eric Ghozlan, Stéphane Gicquel, Laurent Simeoni, Eric Labonne, Michel Gentile, Jean Pierre Tourtier, Catherine Pinson, Florence Foulon, Carole Damiani, Françoise Rudetzki, Laurent Kosorotoff, Anne Gallay, Thierry Cardoso, Jean Claude Desenclos, Clothilde Hachin, Julien Sonnesi, Catherine Isserlis, Nadine Weissleib, Laurent Castra, Claude Evin and François Bourdillon. A special thank to Bruno Falissard, Nathalie Prieto, Louis Jehel, François Ducrocq, Humbert Boisseaux, Jean Jacques Chavagnat, Christine Chan-Chee; and Frederique Rougier for their field investigation, as well as Cecile Vuillermoz, Lise Stein and Jude Sweeney for their careful reading of the final manuscript. 


\section{References}

1 Chipman KJ, Palmieri PA, Canetti D, Johnson RJ, Hobfoll SE. Predictors of posttraumatic stress-related impairment in victims of terrorism and ongoing conflict in Israel. Anxiety Stress Coping 2011; 24: 255-71.

2 Gabriel R, Ferrando L, Cortón ES, Mingote C, García-Camba E, Liria AF, et al. Psychopathological consequences after a terrorist attack: an epidemiological study among victims, the general population, and police officers. Eur Psychiatry J 2007; 22: 339-46.

3 Galea S, Ahern J, Resnick H, Kilpatrick D, Bucuvalas M, Gold J, et al. Psychological sequelae of the September 11 terrorist attacks in New York City. N Engl J Med 2002; 346: 982-7.

4 Verger P, Dab W, Lamping DL, Loze J-Y, Deschaseaux-Voinet C, Abenhaim L, et al. The psychological impact of terrorism: an epidemiologic study of posttraumatic stress disorder and associated factors in victims of the 1995-1996 bombings in France. Am J Psychiatry 2004; 161: 1384-9.

5 Aakvaag HF, Thoresen S, Wentzel-Larsen T, Roysamb E, Dyb G. Shame and guilt in the aftermath of terror: the Utøya Island study. J Trauma Stress 2014; 27: 618-21.

6 Dyb G, Jensen TK, Nygaard E, Ekeberg O, Diseth TH, Wentzel-Larsen T, et al. Posttraumatic stress reactions in survivors of the 2011 massacre on Utøya Island, Norway. Br J Psychiatry 2014; 204: 361-7.

7 Galea S, Vlahov D, Resnick H, Ahern J, Susser E, Gold J, et al. Trends of probable post-traumatic stress disorder in New York City after the September 11 terrorist attacks. Am J Epidemiol 2003; 158: 514-24.

8 Wilson LC. A systematic review of probable posttraumatic stress disorder in first responders following man-made mass violence. Psychiatry Res 2015; 229 : 21-6.

9 Gupta MA. Review of somatic symptoms in post-traumatic stress disorder. Int Rev Psychiatry 2013; 25: 86-99.

10 Santiago PN, Ursano RJ, Gray CL, Pynoos RS, Spiegel D, Lewis-Fernandez R, et al. A systematic review of PTSD prevalence and trajectories in DSM-V defined trauma exposed populations: intentional and non-intentional traumatic events. PLOS ONE 2013; 8: e59236.

11 Kessler RC, Sonnega A, Bromet E, Hughes M, Nelson CB. Posttraumatic stress disorder in the National Comorbidity Survey. Arch Gen Psychiatry 1995; 52: 1048-60.

12 Krysinska K, Lester D. Post-traumatic stress disorder and suicide risk: a systematic review. Arch Suicide Res 2010; 14: 1-23.

13 Gradus, Qin P, Lincoln AK, Miller M, Lawler E, Sørensen HT, et al. 2010 Posttraumatic stress disorder and completed suicide. Am J Epidemiol 2010; 171: $721-7$.

14 Rouillon F, Barrier G, Baruffol E, Benayoun S, Chambon E, Evrard M, et al. Presentation of the epidemiological study of the health consequences of terror attacks. J Int Vict 2003

15 Bonde JP, Utzon-Frank N, Bertelsen M, Borritz M, Eller NH, Nordentoft M, et al. Risk of depressive disorder following disasters and military deployment: systematic review with meta-analysis. Br J Psychiatry 2016; 208: 330-6.
16 Broadhead WE, Gehlbach SH, de Gruy FV, Kaplan BH. The duke-UNC functional social support questionnaire. Measurement of social support in family medicine patients. Med Care 1988; 26: 709-23.

17 Abenhaim L, Dab W. Posttraumatic stress disorder and completed suicide. Study of civilian victims of terrorist attacks (France 1982-1987). J Clin Epidemiol 1992; 45: 103-9.

18 Jehel I, Duchet C, Paterniti S, Consoli SM, Guelfi JD. Prospective study of posttraumatic stress in victims of terrorist attacks. L'Encephale 2001; 27: 393-400.

19 American Psychiatric Association. Diagnostic and Statistical Manual of Mental Disorder (5th edn) (DSM-5). APA, 2013.

20 Bracha HS, Williams AE, Haynes SN, Kubany ES, Ralston TC, Yamashita JM. The STRS (Shortness of breath, Tremulousness, Racing heart, and Sweating): a brief checklist for acute distress with panic-like autonomic indicators; development and factor structure. Ann Gen Hosp Psychiatry 2004; 3: 8

21 Birmes P, Brunet A, Benoit M, Defer S, Hatton L, Sztulman H, et al. Validation of the Peritraumatic Dissociative Experiences Questionnaire self-report version in two samples of French-speaking individuals exposed to trauma. Eur Psychiatry J 2005; 20: 145-51.

22 Leon AC, Olfson M, Portera L, Farber L, Sheehan DV. Assessing psychiatric impairment in primary care with the sSheehan dDisability sScale. Int $J$ Psychiatry Med 1997; 27: 93-105.

23 Duffy M, Gillespie K, Clark DM. Post-traumatic stress disorder in the context of terrorism and other civil conflict in Northern Ireland: randomised controlled trial. BMJ 2007: 334: 1147 .

24 US Department of Veterans Affairs National Center for PTSD. Using the PTSD Checklist for DSM-IV (PCL). US Department of Veterans Affairs National Center for PTSD, 2012 (https://www.ptsd.va.gov/professional/assessment/ documents/PCL_handoutDSM4.pdf).

25 Sheehan DV, Lecrubier $Y$, Sheehan $\mathrm{KH}$, Amorim P, Janavs J, Weiller E, et al. The Mini-International Neuropsychiatric Interview (M.I.N.I.): the development and validation of a structured diagnostic psychiatric interview for DSM-IV and ICD-10. J Clin Psychiatry 1998; 59 (suppl 20): 22-33.

26 Busner J, Targum SD. The Clinical Global Impressions scale. Psychiatry (Edgmont) 2007; 4: 28-37

27 Salguero JM, Fernández-Berrocal P, Iruarrizaga I, Cano-Vindel A, Galea S. Major depressive disorder following terrorist attacks: a systematic review of prevalence, course and correlates. BMC Psychiatry 2011; 11: 96.

28 Bleich A, Gelkopf M, Solomon Z. Exposure to terrorism, stress-related mental health symptoms, and coping behaviors among a nationally representative sample in Israel. JAMA 2003; 290: 612-20.

29 Gidron Y, Kaplan Y, Velt A, Shalem R. Prevalence and moderators of terrorrelated post-traumatic stress disorder symptoms in Israeli citizens. Isr Med Assoc J 2004; 6: 387-91.

30 Milligan-Saville JS, Paterson HM, Harkness EL, Marsh AM, Dobson M, Kemp RI, et al. The amplification of common somatic symptoms by posttraumatic stress disorder in firefighters. J Trauma Stress 2017; 30: 142-148.

31 Elhai JD, Jacobs GA, Kashdan TB, DeJong GL, Meyer DL, Frueh BC. Mental health service use among American Red Cross disaster workers responding to the September 11, 2001 U.S. terrorist attacks. Psychiatry Res 2006; 143(1): 29-34. 